\title{
OpEEr - Optimising the energy efficiency of buildings through individual room temperature control
}

\author{
Igor Mojic ${ }^{*}$ and Michel Haller ${ }^{1}$ \\ ${ }^{1}$ Institute for Solar Technology SPF, University of Applied Sciences (HSR), CH-8640 Rapperswil, Switzerland
}

\begin{abstract}
In Switzerland, the standard SIA 384/1 (based on SN EN 12828) does not require individual room temperature control for new buildings or very well refurbished buildings with space heating supply temperatures below $30^{\circ} \mathrm{C}$. This is justified by the so-called "self-regulating effect", which means that when the room temperature increases the heat input into the room is reduced due to the decreasing temperature difference between the hydronic heating system and the room. According to the new regulations of the Swiss cantons (MuKEn 2014), at least a reference room temperature control is prescribed. However, it is still unclear whether and when the individual cantons will adopt this regulation. This study compares the three most common variants for room temperature control using dynamic simulations. The simulations show that the self-regulating effect cannot sufficiently reduce the heat input into the room, and that a reference room control is not only energetically more efficient, but also economically more attractive. Individual room control performs better than reference room control in terms of comfort and final energy consumption. A further finding from the project is that the heat requirement for an apartment of a multi storey building depends strongly on the temperatures with which the storeys below and above are heated. Under certain circumstances, the ratio of the total building heat requirement for an apartment of the storey in the middle can be reduced from $20 \%$ to $1 \%$. In the project, recommendations for building owners and authorities regarding room temperature control were worked out.
\end{abstract}

\section{Introduction}

In Switzerland, according to the Swiss standard SIA 384/1 [1] that is based on the EN 12828 [2], individual room control can be waived for new buildings or very well renovated buildings with space heating supply temperatures below $30^{\circ} \mathrm{C}$. The reason for this is the so-called "self-regulating effect", which means that at higher room temperatures the heat input into the room is reduced due to the decreasing temperature difference between the hydronic heating system and the room. It is assumed that, for well insulated residential buildings, the reduction of this temperature difference, e.g. due to passiv solar gains, is sufficient to limit the heat input into the corresponding room. No specific studies of this effect have been found, but a lot of descriptions from associations like suissetec (Swiss HVAC Association) or the German association for surface heating and cooling (BVF). Thus, there are no scientific findings that the self-regulating effect is sufficient to prevent overheating in buildings. However, the new Swiss regulations (MuKEn 2014 [3]) require that at least a reference room control per apartment is installed. Some Swiss cantons have adopted the new regulations, but it is still unclear whether and when the individual cantons will adopt this regulation. It cannot be excluded that in future individual cantons may not change to the new regulations. Therefore, in this project, the three most common room control options were analysed in detail with dynamic annual simulations, which are the reference room control, individual room control and no room temperature control.

An individual room control that is independent of the supply temperature is prescribed in the EU Directive 2018/844 [4]. In the review of Lomas et. al. [5] the benefits of room temperature control have been analysed in a systematic way. It was not found any reasonable evidence about the positive impact on energy savings of any of the heating controls studied. It is noticeable that the focus of almost all studies lies on room temperature control in relation to radiators and older buildings. Actually, hardly any information and studies about the effect of different room temperature controls on buildings with hydronic floor heating systems can be found. This is surprising, since especially in Europe (e.g. Switzerland, Germany, Austria) new buildings are realized with hydronic floor heating systems due to the good performance with low space heating supply temperatures (e.g. heat pumps). In the project "OpEEr", the self-regulating effect, the individual room control and the reference room control were compared regarding multi-family houses (MFH). The present study is preceded by two further studies by Mojic \& Mojic et. al. $[6,7]$, in which these control types for single-family houses were investigated in particular.

\footnotetext{
*Corresponding author: igor.mojic@spf.ch
} 


\section{Methodology}

\subsection{General}

The comparison of the three control types was carried out by means of dynamic annual simulations with the building simulation program IDA ICE v.4.8. The advantage of simulations is that always the same conditions prevail and one can compare technologies without the influence from other aspects like different user behaviour or climate. The difficulty of simulations is to choose and parameterize the models as realistically as possible. In the following chapters, the assumptions about the building and the HVAC system are described in detail.

\subsection{Reference Building}

The reference building model is based on the detailed analysis of $65 \mathrm{MFH}$ in the project ImmoGap [8]. The standard heating demand of the massive building is $29 \mathrm{kWh} / \mathrm{m}^{2}$ a. The building has three inhabited storeys and six apartments with an energy reference area of total 1'205 $\mathrm{m}^{2}$. The shape factor (see Eq. 1) is 1.3 and the window ratio of the energy reference area is $25.1 \%$. The building has a mechanical ventilation with a heat recovery efficiency of $80 \%$. Further details about the reference building can be found in the final report of the project [9]. Fig. 1 shows a 3D image of the building, implemented in the simulation software IDA ICE. Rather than assuming a standard user behaviour, one that more closely corresponds to the real user behaviour as derived from the project ImmoGap has been used. The result is that the heat demand in spring, summer and autumn is higher than would be expected with standard calculations. The corresponding user behaviour regarding shading control and window opening is as follow:

- Shading control: when the room temperature reaches $20.5^{\circ} \mathrm{C}$ and the radiation reaches $200 \mathrm{~W} / \mathrm{m}^{2}$ on the façade, the g-value of the window is reduced to 0.06 .

- Window opening control: In the transition and summer period (March to October), one window per apartment is tilted (10\% of the area is open) in the night $(20.00-07.00)$.

The internal gains are standard values from the Swiss standard SIA 2024 [10]. The heating load per zone was calculated with Lesosai v.2018 based on the standard SIA 384.201 [11]. The volume flow of the mechanical ventilation is based on guidelines of the Swiss building label Minergie [12].

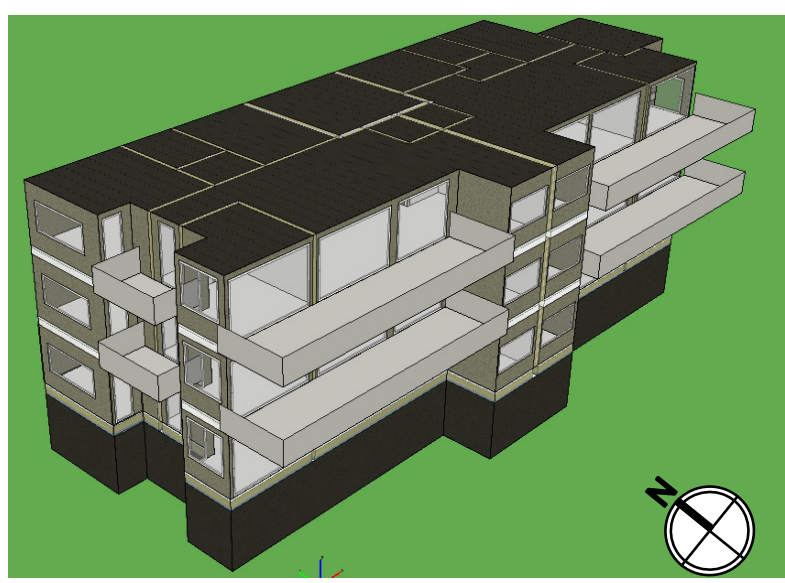

Fig. 1. 3D illustration of the reference building in IDA ICE

Table 1. Selected key parameters of the modelled reference building.

\begin{tabular}{|c|c|c|}
\hline Parameter & Value & Unit \\
\hline Standard Heating Demand & 29 & $\mathrm{kWh} / \mathrm{m}^{2} \mathrm{a}$ \\
\hline $\begin{array}{l}\text { Reference Energy Area } \\
\text { (REA) }\end{array}$ & 1'205 & $\mathrm{m}^{2}$ \\
\hline $\begin{array}{l}\text { Window Ratio } \\
\text { (relating to REA) }\end{array}$ & 25.1 & $\%$ \\
\hline U-Value: outside wall & 0.18 & $\mathrm{~W} / \mathrm{m}^{2} \mathrm{~K}$ \\
\hline $\begin{array}{l}\text { U-Value: inside wall } \\
\text { (same apartment) }\end{array}$ & 2.6 & $\mathrm{~W} / \mathrm{m}^{2} \mathrm{~K}$ \\
\hline $\begin{array}{l}\text { U-Value: inside wall } \\
\text { (between apartments) }\end{array}$ & 0.6 & $\mathrm{~W} / \mathrm{m}^{2} \mathrm{~K}$ \\
\hline U-Value: roof & 0.18 & $\mathrm{~W} / \mathrm{m}^{2} \mathrm{~K}$ \\
\hline $\begin{array}{c}\text { U-Value: } \\
\text { intermediate floor }\end{array}$ & 0.64 & $\mathrm{~W} / \mathrm{m}^{2} \mathrm{~K}$ \\
\hline U-Value: window & $0.85-1.0$ & $\mathrm{~W} / \mathrm{m}^{2} \mathrm{~K}$ \\
\hline g-value (window) & 0.45 & - \\
\hline Thermal Bridge Losses & 90.8 & $\mathrm{~W} / \mathrm{K}$ \\
\hline Constant Infiltration & 0.16 & $\mathrm{~m}^{3} / \mathrm{m}^{2} \mathrm{~h}$ \\
\hline
\end{tabular}

The shape factor (SF) is calculated as follows:

$$
S F=A_{t h} / \cdot A_{E}
$$

where $A_{\text {th }}$ is the thermal enveloping surface of the building and $A_{E}$ is the energy reference area. 


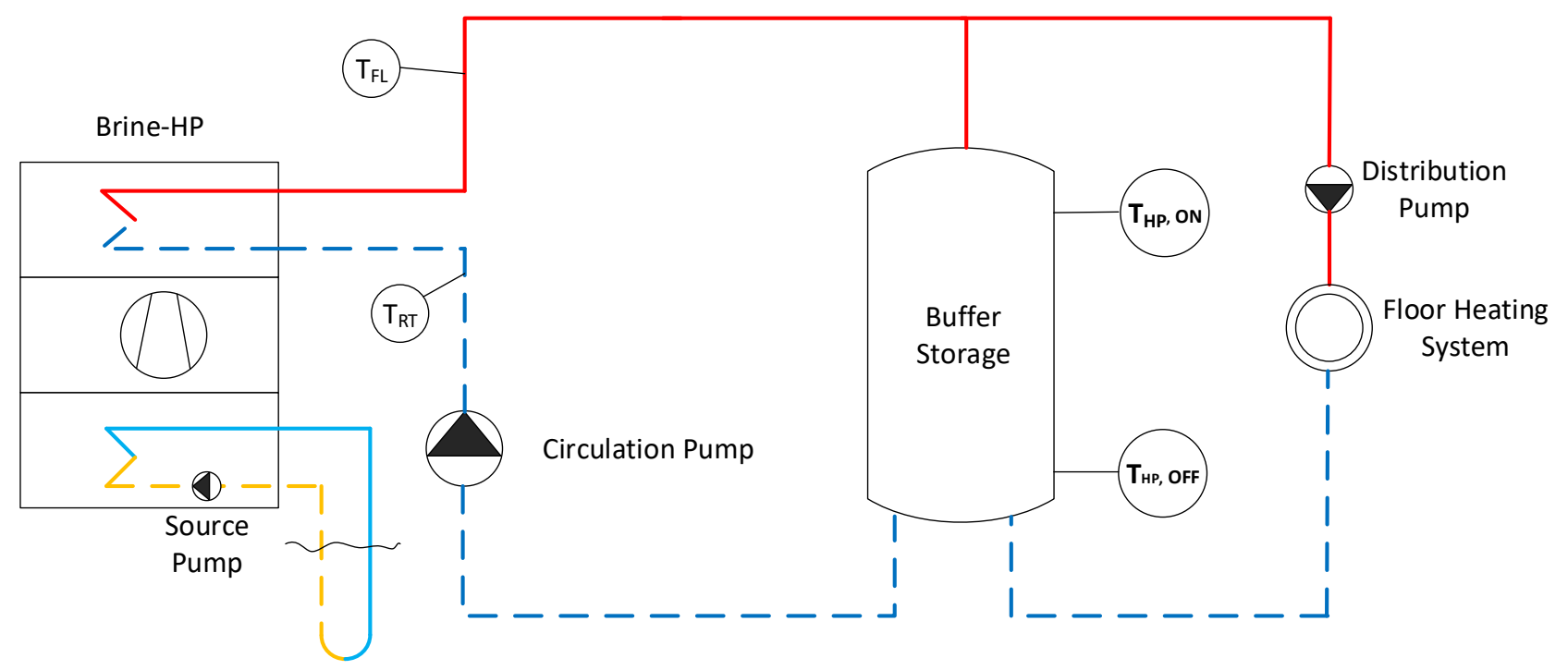

Fig. 2. Hydraulic schema of the modelled heating system in IDA ICE

\subsection{Heating system}

A heat pump (HP) was chosen as a heat generator, firstly because this is the dominant type of heat generator for new buildings in Switzerland, but also because it is sensitive to temperatures and flow rates and therefore the most interesting in terms of handling different room temperature controls which can influence the flow. The heating system was modelled to analyse the impact of the different control types on the final energy demand and also on the behaviour of the heating system (e.g. On/Off characteristics). The most important parameters of the heating system are described in Table 2. In Fig. 2 a hydraulic schema of the system is shown. The heat pump has one compressor with constant speed and is modelled with the standard IDA ICE type for brine source heat pumps. The heat pump and the circulating pump switch on if the difference between the temperature at the top of the storage $\left(\mathrm{T}_{\mathrm{HP}, \mathrm{ON}}\right)$ and the demanded heating supply temperature from the heating curve drops below $0.5 \mathrm{~K}$. If the set temperature is reached at the bottom of the storage $\left(\mathrm{T}_{\mathrm{HP}, \mathrm{OFF}}\right)$, both components were switched off. The distribution pump switches on when the mean ambient temperature (24 hour) is below the heating limit of $17^{\circ} \mathrm{C}(2 \mathrm{~K}$ hysteresis). The chosen heating limit is rather high compared to Swiss standards $\left(12^{\circ} \mathrm{C}\right)$, but it correspondents to the evaluation of $65 \mathrm{MFH}$ in the project ImmoGap. The flow rate of the distribution pump is controlled with the constant pressure drop method. That means that the flow rate is reduced when the room temperature control closes the valves in the floor distribution due to rising room temperatures.

For the heat distribution, the standard hydronic floor heating model of IDA ICE was used that is based on the steady-state thermal resistance method of EN 15377-1 [13]. The heating curve, which defines the set point temperature for the supply temperature, is shown for a high and a low temperature profile in Fig. 3.
Table 2. Selected key parameters of the modelled heating system.

\begin{tabular}{|c|c|c|}
\hline Parameter & Value & Unit \\
\hline Heating Power (B0/W35) & 30 & $\mathrm{~kW}$ \\
\hline $\begin{array}{c}\text { Coefficient of Performance } \\
\text { (COP at B0/W35) }\end{array}$ & 4.0 & - \\
\hline Volume Storage & 1.0 & $\mathrm{~m}^{3}$ \\
\hline $\begin{array}{c}\text { Design Flow of the Heat } \\
\text { Distribution Pump }\end{array}$ & $3{ }^{\prime} 247$ & $\mathrm{~kg} / \mathrm{h}$ \\
\hline $\begin{array}{c}\text { Design Flow of the Brine } \\
\text { Source Pump }\end{array}$ & $22^{\prime} 160$ & $\mathrm{~kg} / \mathrm{h}$ \\
\hline $\begin{array}{c}\text { Design Flow of the } \\
\text { Circulating Pump ( } \Delta \mathrm{T} 6 \mathrm{~K})\end{array}$ & $3{ }^{\prime} 960$ & $\mathrm{~kg} / \mathrm{h}$ \\
\hline $\begin{array}{c}\text { Geothermal Probe } \\
\mathrm{g}\end{array}$ & $2 \times 190$ & $\mathrm{~m}$ \\
\hline
\end{tabular}

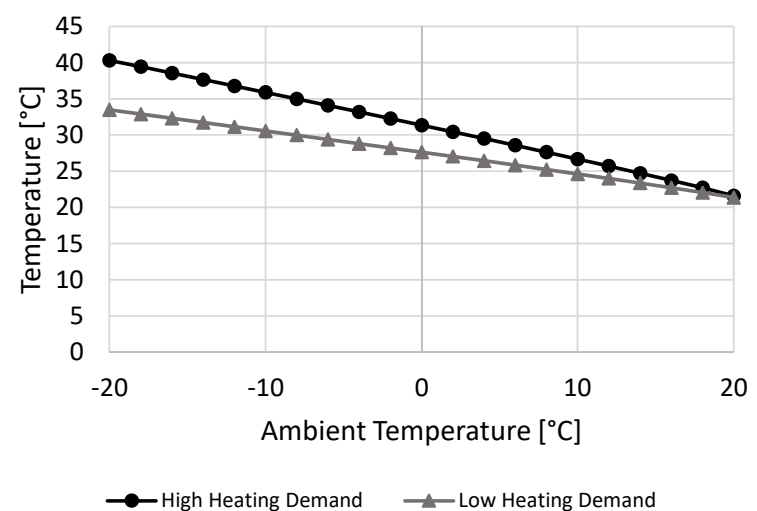

Fig. 3. Design supply temperature in function of the ambient temperature. 


\subsection{Room temperature control}

In the case of the individual room control, thermostatic valves with an On/Off behaviour and a hysteresis of 1 Kelvin were used. According to a Swiss manufacturer, these control units are the most frequently used in apartment buildings. The choice of the hysteresis value has an influence on the heating system (flow rate profile) and also on the comfort. A higher hysteresis results in a larger deviation from the temperature set point and thus greater fluctuation of the room temperatures (Fig. 4). These relationships are explained in more detail in Mojic et al. [7].

In the case without room temperature control (selfregulating effect), all heating circuits in the building are always flowed through with the full flow rate during the heating season.

In comparison to the individual room control, the reference room control is simpler since the temperature measurement and consequently the heat output control do not have to be installed for each individual room. Instead, the heating input for all rooms in an apartment are controlled as a function of a specifically chosen reference room. In general, the living room is selected as the reference room and the temperature is recorded there. In this project, the same control parameters (control behaviour, hysteresis, etc.) are used for reference room control and for individual room control thermostats.

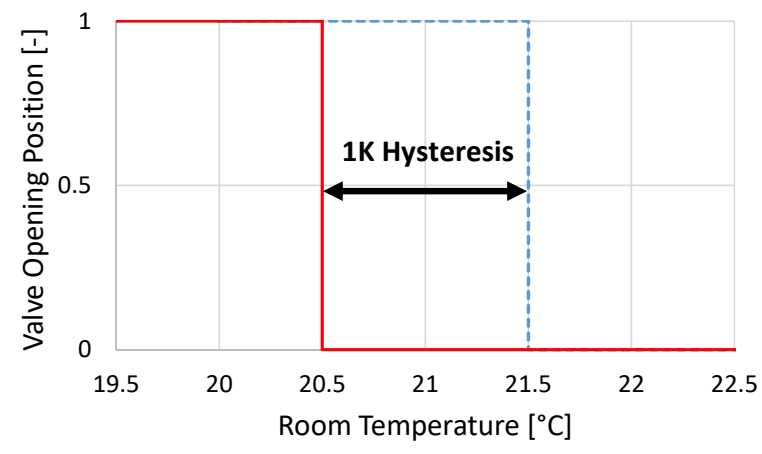

Fig. 4. Control behaviour of the On/Off thermostat for the reference room and individual room temperature control unit.

\subsection{Economic feasibility}

The profitability of the various control variants is evaluated using the equivalent annual cost. This method is based on different assumptions and calculations [14], which are explained below. To evaluate an energy saving measure, the annuity profit is calculated. This is obtained from the difference between annuity proceeds, i.e. energy cost savings, and annuity costs.

The annuity costs of the energy saving measure $(K)$ are calculated with the following formula:

$$
K=a \cdot I+Z
$$

where $I$ are the additional costs for the energy saving measure and $Z$ are the annual maintenance costs. The annuity factor $(a)$ is calculated as follow:

$$
a=i \cdot(1+i)^{n} /\left((1+i)^{n}-1\right)
$$

where $i$ is the required rate of return and $n$ is the expected useful life.

The annuity saving $(E)$ is calculated with the Eq. 4, where $p$ is the mean cost of the energy (here electricity costs) over the examined period, $E_{0}$ is the annual energy demand without room temperature control and $E_{s}$ is the annual energy demand with either reference room control or individual room control.

$$
E=p \cdot\left(E_{0}-E_{s}\right)
$$

An energy saving measure is economical if the annuity gain $(G)$, i.e. the savings $(E)$ minus the cost $(K)$, are greater than zero:

$$
G=E-K=p \cdot\left(E_{0}-E_{s}\right)-(a \cdot I+Z)
$$

The assessment criteria chosen here are particularly suitable for checking the profitability of an investment if the energy savings for the investor can actually be shown as revenue. This is the case if the owner is at the same time the inhabitant. In the case of rented apartments, the benefit of the energy savings in the form of a reduction in heating costs primarily benefits the tenant and not the owner or investor. Only if heating costs are fully transparent and tenants are fully aware of this cost, can additional investment costs that lead to lower heating costs also be an advantage for the investor on the market, as the rent with heating costs reflects the corresponding rent advantage. With regard to legislation, the economic efficiency analysis helps to compare any measures required to save energy with other measures that are already required today.

\section{Results}

In the following chapters, the different types of room temperature control are compared with each other, and the advantages and disadvantages of each of the three control variants analyzed. The evaluation focuses on the following parameters:

- Wel,HP: final energy consumption of the heat pump (electricity consumption)

- HPon/off: On/Off cycles of the heat pump

- Operative temperature

- Qth: heat input in to the zone (room)

- Deceeding time: average number of hours per zone in which the room temperature is below the set point temperature by more than $0.5 \mathrm{~K}$

- Exceeding time: average number of hours per zone in which the set room temperature is exceeded by more than $1.5 \mathrm{~K}$ 
The parameters "Deceeding time" and "Exceeding time" deliberately have an offset of $0.5 \mathrm{~K}$ and $1.5 \mathrm{~K}$ respectively. On the one hand, this takes the hysteresis of the controller into account and, on the other hand, we assume that an overtemperature is rather accepted by the user than an undershoot of the desired temperature.

The open tilt window (see chapter 2.2) is always located in room 1 of the corresponding apartment. In the case of the reference room control, the living room was used for all simulations as reference room for the temperature measurement.

\subsection{Low and homogeneous room temperatures}

In a first step, the three room control types were compared with set temperatures of $21^{\circ} \mathrm{C}$ (individual and reference room control). The reference room control has the lowest electricity consumption $\left(\mathrm{W}_{\mathrm{el}, \mathrm{HP}}\right)$ and the second lowest number of On/Off cycles $\left(\mathrm{HP}_{\mathrm{On} / \mathrm{Off}}\right)$ of the heat pump (Fig. 5 and 6). However, the desired temperatures are less well maintained (Fig. 7). The number of hours during which the room target temperatures are undercut by more than $0.5 \mathrm{~K}$ is more than $700 \mathrm{~h}$ per room on average. This is almost factor 7.5 more compared to individual room control. Since it can be assumed that the occupants adjust their set point in order to maintain pleasant temperatures in all zones, a further simulation with increased set temperature of $22{ }^{\circ} \mathrm{C}$ was carried out for the reference room control. By increasing the set temperatures, the hours with too low temperatures are massively reduced to $\sim 100$ hours and the electrical energy consumption of the heat pump increases by 1 ' $242 \mathrm{kWh}(+13 \%)$ compared to the simulation with set temperature $21^{\circ} \mathrm{C}$, and is thus $931 \mathrm{kWh}(+10 \%)$ higher than in the case of individual room control.

The electrical consumption of the heat pump is 3'551 kWh (-41\%) lower with an individual room control compared to the simulation without room control, which relies only on the self-regulating effect. In contrast, the simulation without room control has significantly fewer On/Off cycles of the heat pump (-63\%), which ultimately leads to lower losses of the heat pump in practice. However, this was not taken into account in the simulation model.

If one considers the temperature distribution (Fig. 10) in the zones without room temperature control, it becomes apparent that these zones have significantly higher room temperatures than those with room temperature control, which also leads to the high number of hours the set temperature is exceeded (Fig. 8). This makes it clear that the so-called self-regulating effect with a supply temperature of $30^{\circ} \mathrm{C}$ cannot reduce the heat input sufficiently to prevent an excess temperature in the rooms. Apartments between two other storeys in particular have much higher room temperatures than set on the controller, as the losses via the building envelope are significantly lower than for apartments located on the ground floor or underneath the roof. This also explains the increased electricity consumption of the heat pump in the case without room control, as the heat input is much greater due to insufficient temperature control.

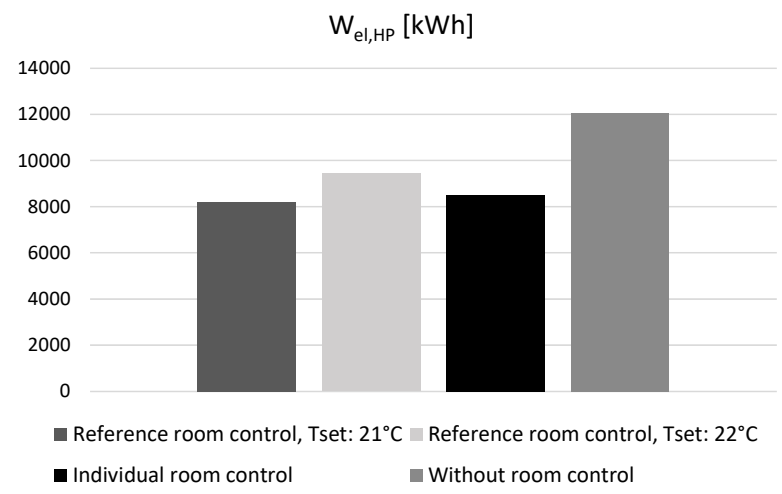

Fig. 5. Electricity use of the HP for different control strategies.

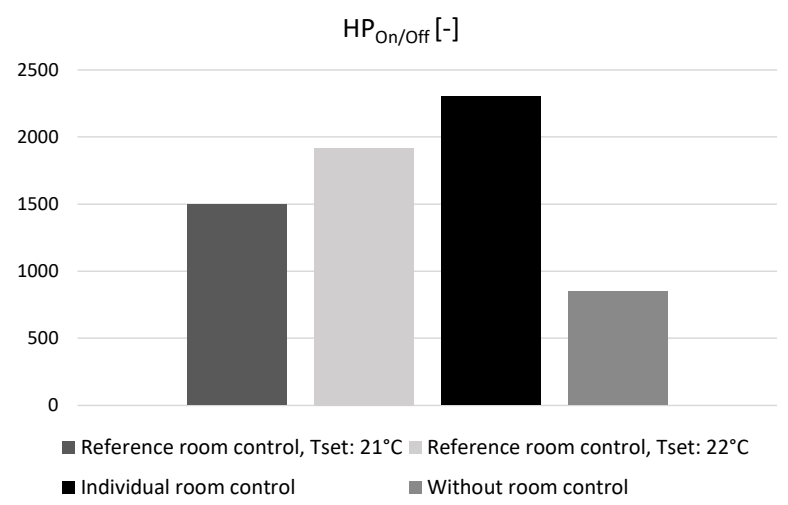

Fig. 6. On/Off cycles of the HP for different control strategies.

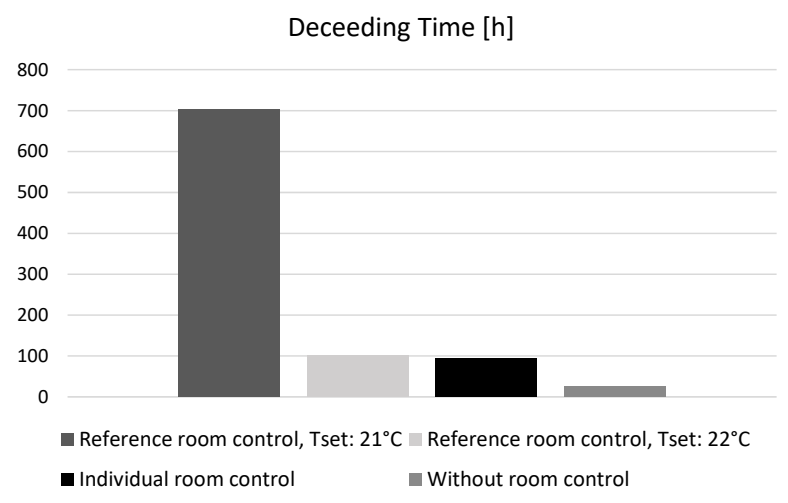

Fig. 7. Average hours per zone in which the room temperature is $0.5 \mathrm{~K}$ below set temperature.

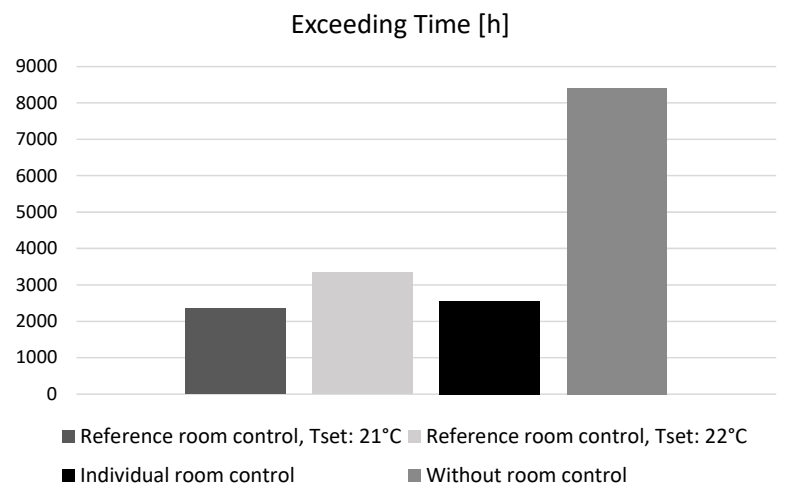

Fig. 8. Average hours per zone in which the room temperature is $1.5 \mathrm{~K}$ above set temperature. 


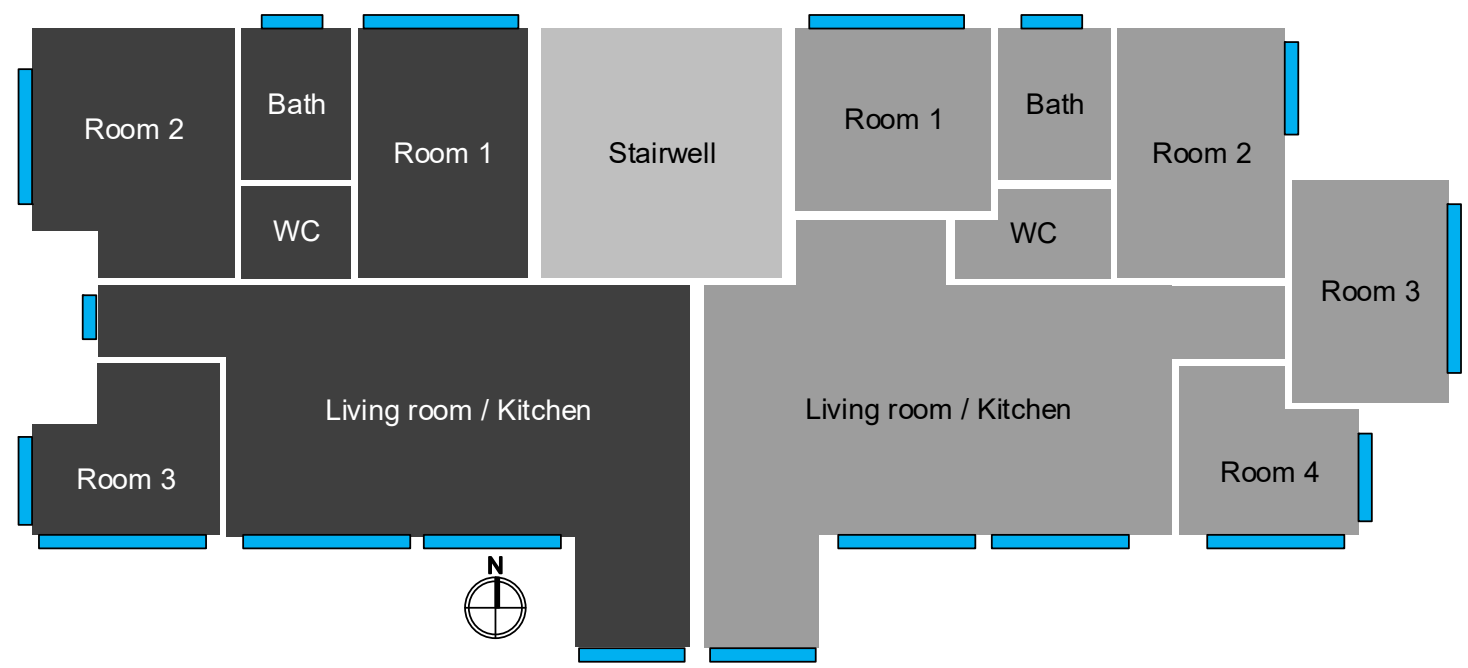

Fig. 9. Floor plan of the reference building for all floor levels.
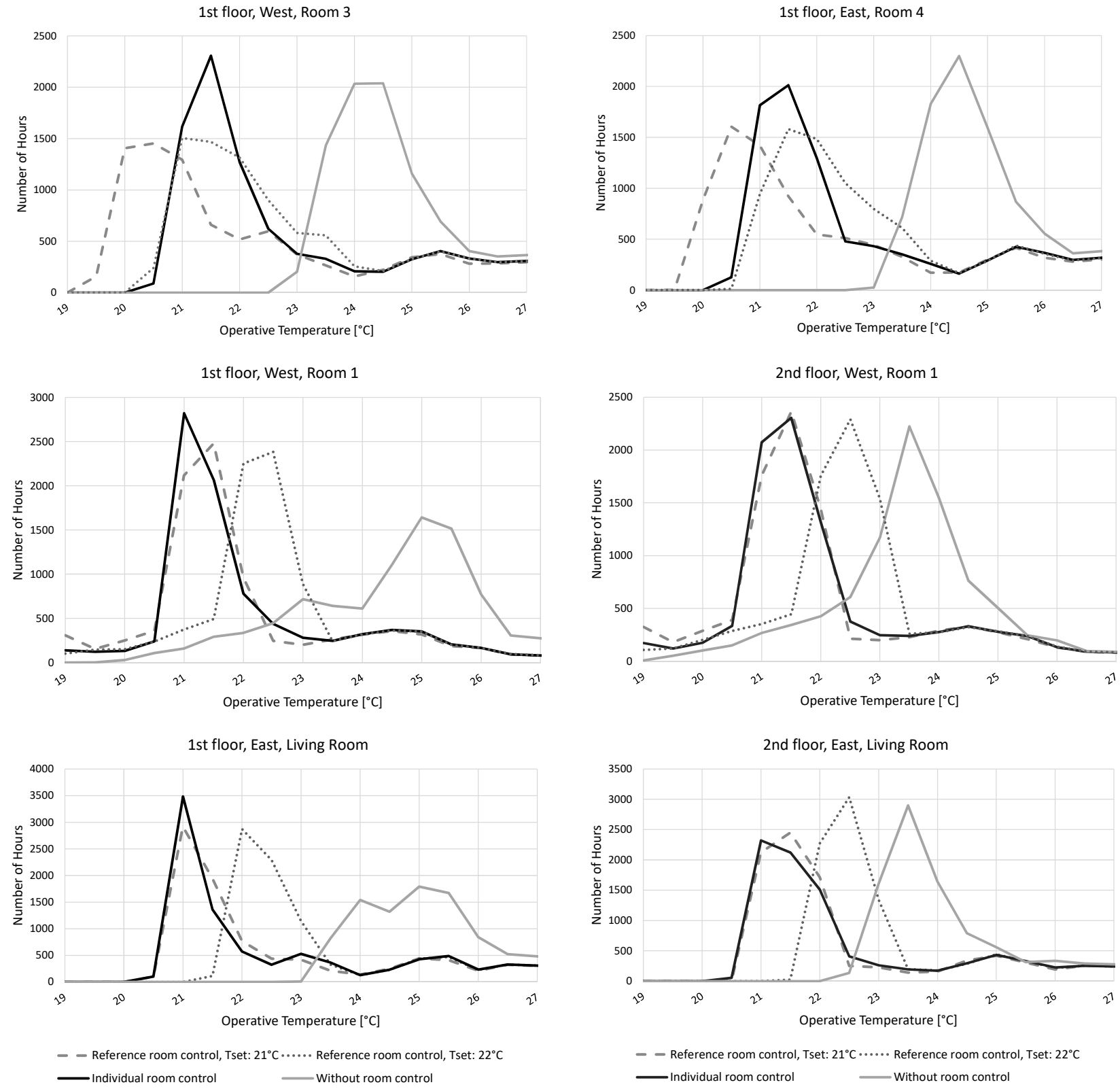

Fig. 10. Temperature frequency for selected zones and different room temperature control types with a design supply temperature of $30{ }^{\circ} \mathrm{C}$ (floor heating system). 


\subsection{Higher and inhomogeneous room temperatures}

It is very unlikely that the residents of a MFH will set all their room thermostats to $21^{\circ} \mathrm{C}$ [8]. For this reason, a comparison of the room control types with increased room temperatures was carried out. The zones/apartments have a target temperature of $24^{\circ} \mathrm{C}$ on the entire ground floor and on the second floor. The floor in between (first floor) has a set temperature of $21^{\circ} \mathrm{C}$. In order to achieve the higher room temperatures, the design supply temperature was increased from $30{ }^{\circ} \mathrm{C}$ to $35^{\circ} \mathrm{C}$ (at $-8{ }^{\circ} \mathrm{C}$ ambient temperature), which is usually done in practice to meet the comfort requirements of the residents. Regardless of the type of control, room temperatures of $24{ }^{\circ} \mathrm{C}$ with a supply temperature of $30{ }^{\circ} \mathrm{C}$ were not achieved everywhere on the second floor. The simulation results in Fig. 11 show that the difference between the reference room control and the individual room control is negligible in terms of electricity consumption. In contrast, the comparison between individual room control and the case without room temperature control is very high with a difference of 4’088 kWh $(+33 \%$ without room temperature control). Once again, the number of hours during which the temperature falls below the set temperature by more than $0.5 \mathrm{~K}$ is much higher for the reference room control. This is mainly due to the fact that the room temperatures are not maintained as well as with individual room control. This can be seen for the different floors in Fig. 16. Therefore, a further simulation with increased supply temperature $(+2 \mathrm{~K})$ and increased set temperatures for the ground floor $(+0.5 \mathrm{~K})$ was carried out. This reduces the deceeding time significantly, but not completely to the level of the individual room control. By increasing the temperatures, the reference room control requires $538 \mathrm{kWh}(+4 \%)$ more electrical energy than the individual room control.

Due to the higher supply temperature, the room temperatures rise again significantly when there is no room control, as can be seen in Fig. 16. This is not surprising, as the self-regulating effect only begins to take effect at higher room temperatures. It is clear that buildings without room temperature control are massively more susceptible to changes in heat distribution parameters and are therefore much more demanding in operation management.

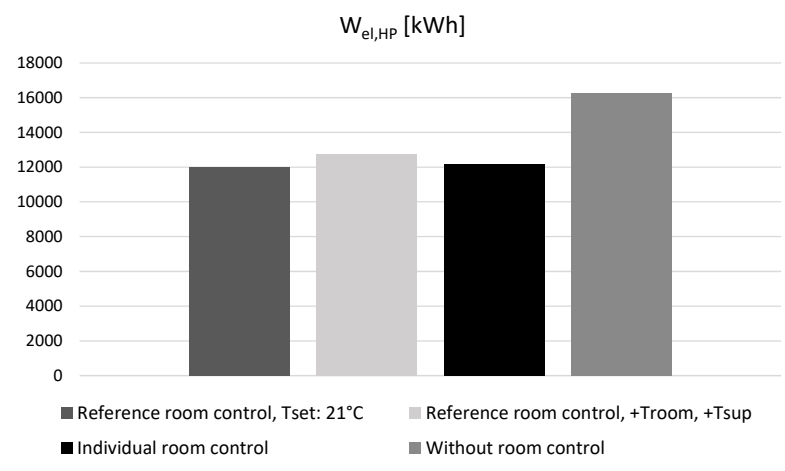

Fig. 11. Electricity use of the HP for different control strategies.

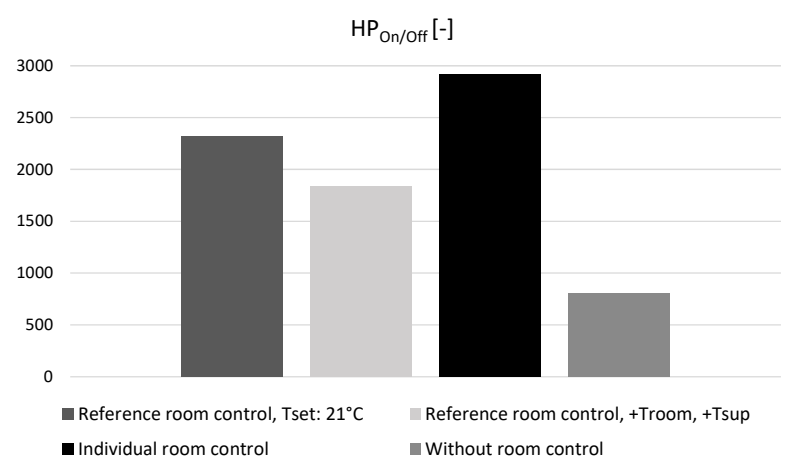

Fig. 12. On/Off cycles of the HP for different control strategies.

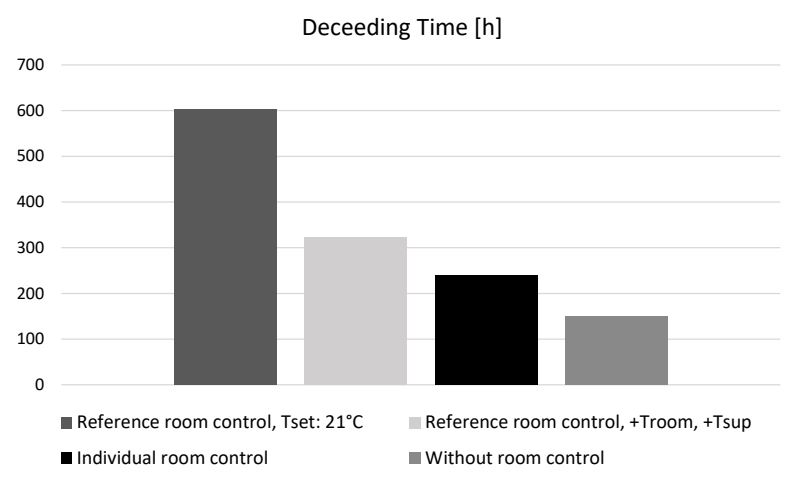

Fig. 13. Average hours per zone in which the room temperature is $0.5 \mathrm{~K}$ below set temperature.

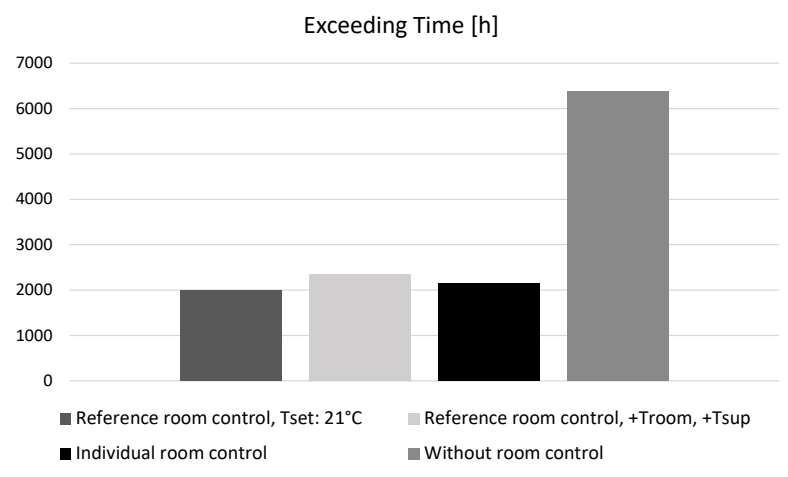

Fig. 14. Average hours per zone in which the room temperature is $1.5 \mathrm{~K}$ above set temperature. 


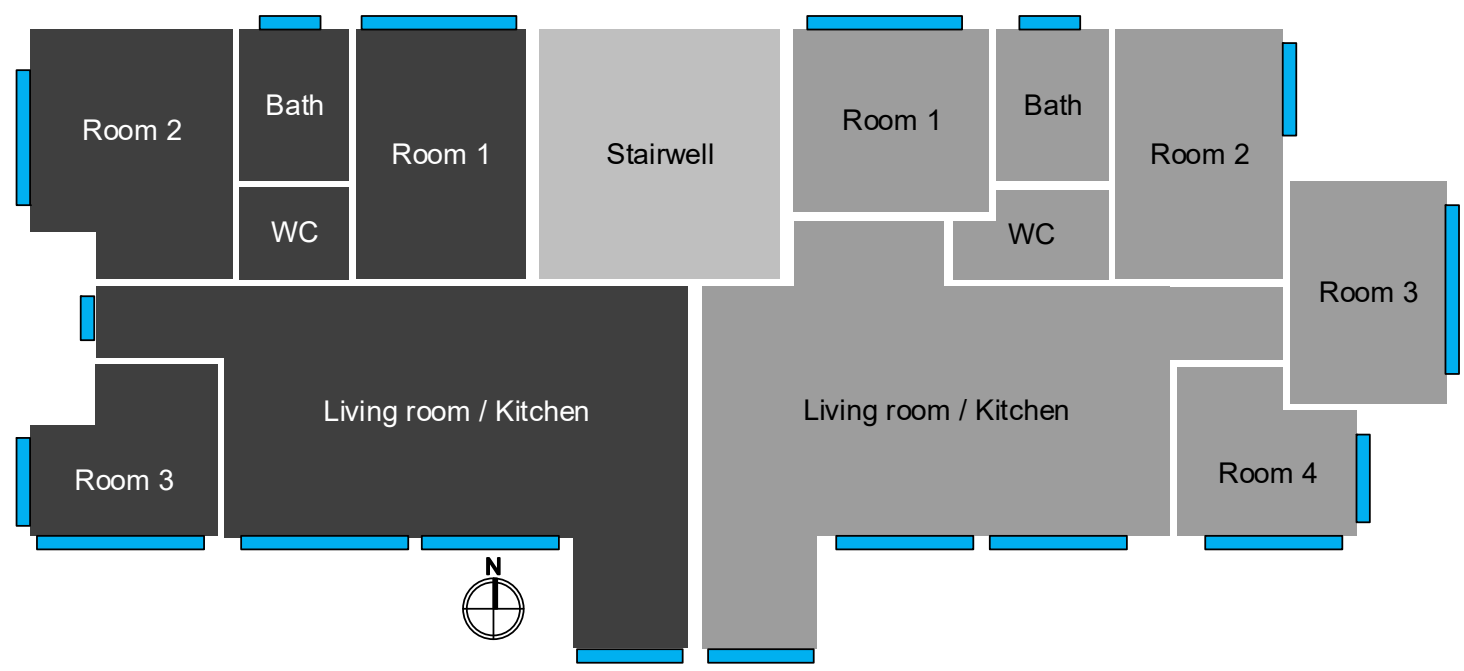

Fig. 15. Floor plan of the reference building for all floor levels.
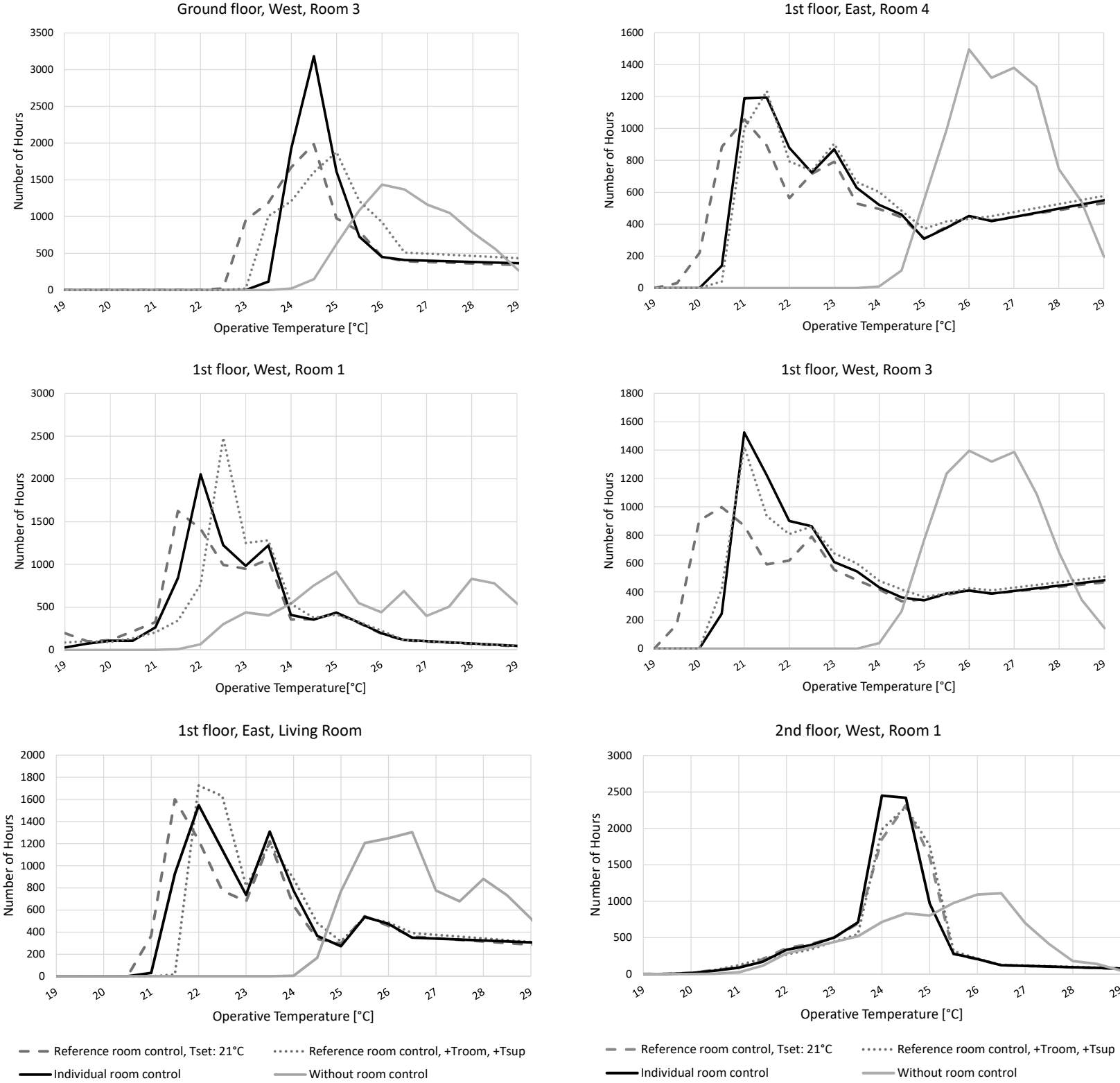

Fig. 16. Temperature frequency for selected zones and different room temperature control types with a design supply temperature of $35^{\circ} \mathrm{C}$ (floor heating system) and different set point temperatures for the ground floor and the $2^{\text {nd }}$ floor. 


\subsection{Heat exchange between the apartments}

When evaluating the heat exchange between the apartments, it is noticeable that there are cases in which an apartment in a storey between other storeys has an extremely low heat requirement and higher temperatures than desired. Both our own experience and conversations with residents of apartment buildings living on storeys between others confirm the findings from the simulation. Often the room temperature cannot be lowered at all, without setting the thermostat settings almost to the minimum, which may not be allowed for reasons of: "Heat theft" and building damage avoidance e.g. mould. Fig. 17 shows the heat transfer of the underfloor heating for four different simulations with reference room control. A distinction is made between heat that is transferred from the hydronic heating system to the desired room (upward) and heat that goes to the zone below (negative value). The first two graphs show the heat flow for the simulations with homogeneous zone temperatures of $21{ }^{\circ} \mathrm{C}$ (left) and $24{ }^{\circ} \mathrm{C}$ (right) in all storeys and all rooms. Regardless of the temperature set point, the demand for the $2^{\text {nd }}$ floor (underneath the roof) is clearly the greatest with a share of the total heat demand of $52 \%$ (zone temp. $=21^{\circ} \mathrm{C}$ ) and $49 \%$ (zone temp. $\left.=24{ }^{\circ} \mathrm{C}\right)$. The first floor between the others has a share of $20 \%$.

If it is assumed that a higher target temperature $(+3 \mathrm{~K})$ is set on the ground floor and second floor compared to the storey in the middle ( $1^{\text {st }}$ floor), the share of the total heat requirement on the floor in the middle is only $1 \%$. As
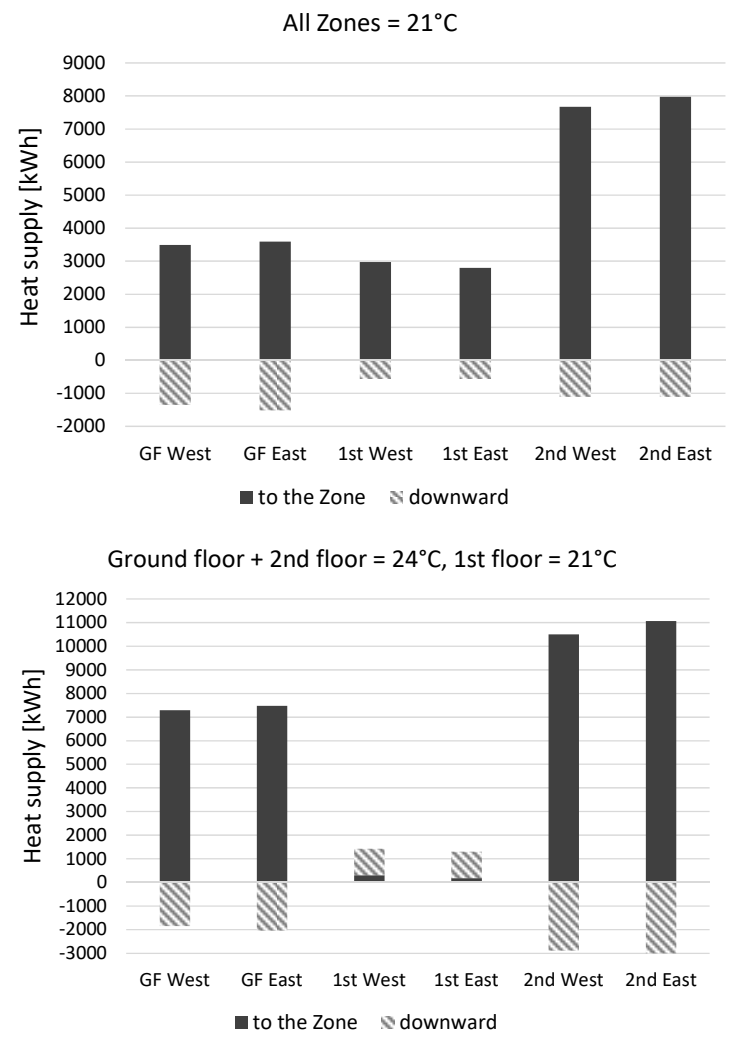

can be seen in the graphic at the bottom left, the bar for the middle floor becomes positive, which means that heat flows upwards from the floor below through the hydronic floor heating distribution. This reduces the heat requirement in the first floor by a total of 6' $444 \mathrm{kWh}(-$ $93 \%$ ), and in turn increases the heat requirement on the ground floor by $4^{\prime} 049 \mathrm{kWh}(+28 \%)$ and on the second floor by 3'205 kWh (+13\%). This means that the heating costs for residents with higher room temperatures rise not only because of higher losses to the ambient outdoors, but also because of losses to neighbouring apartments with lower temperature set points. The underfloor heating of the middle floor is hardly active if the apartments above and below are heated to higher temperatures.

Fig. 18 shows the temperature curves for the eastern apartment on the first floor for the simulations with homogeneous target temperature in all zones $\left(21^{\circ} \mathrm{C}\right)$. One can recognize that the temperatures exceed the target value clearly more frequently if the apartments above and below have higher room temperatures. One consequence of this could be that the residents on the first floor more frequently correct an excessively high room temperature via window ventilation. This would have the consequence that the additional consumption of heat would rise clearly, which could explain part of the "energy performance gap" in apartment buildings (hypothesis). It can also be seen that the first floor meets the minimum temperature requirements at almost any time, even if the underfloor heating is hardly active. The heat transfer from the apartments above and below is sufficient.

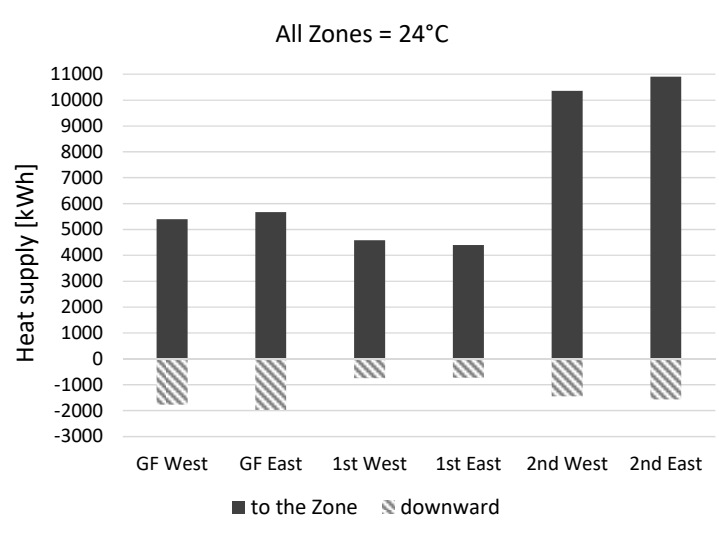

Ground floor +2 nd floor $=24^{\circ} \mathrm{C}, 1$ st floor $=18^{\circ} \mathrm{C}$

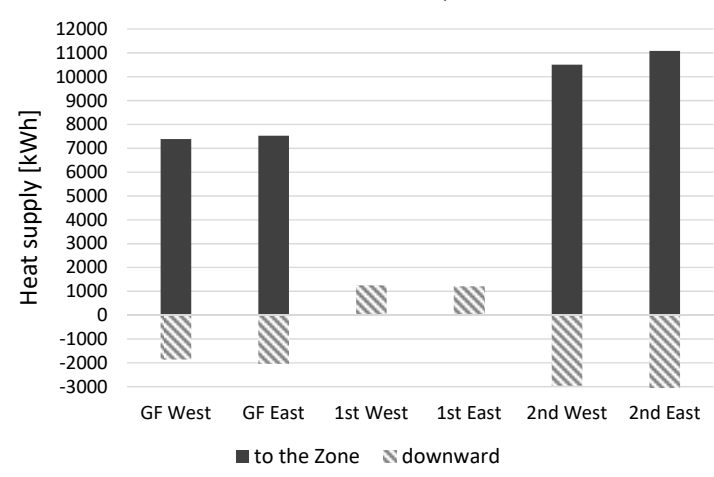

Fig. 17. Heat balance of the hydronic floor heat distribution for each storey and for four different temperature settings, simulated with reference room control and supply temperatures of $35^{\circ} \mathrm{C}(\mathrm{GF}=$ ground floor $)$. 

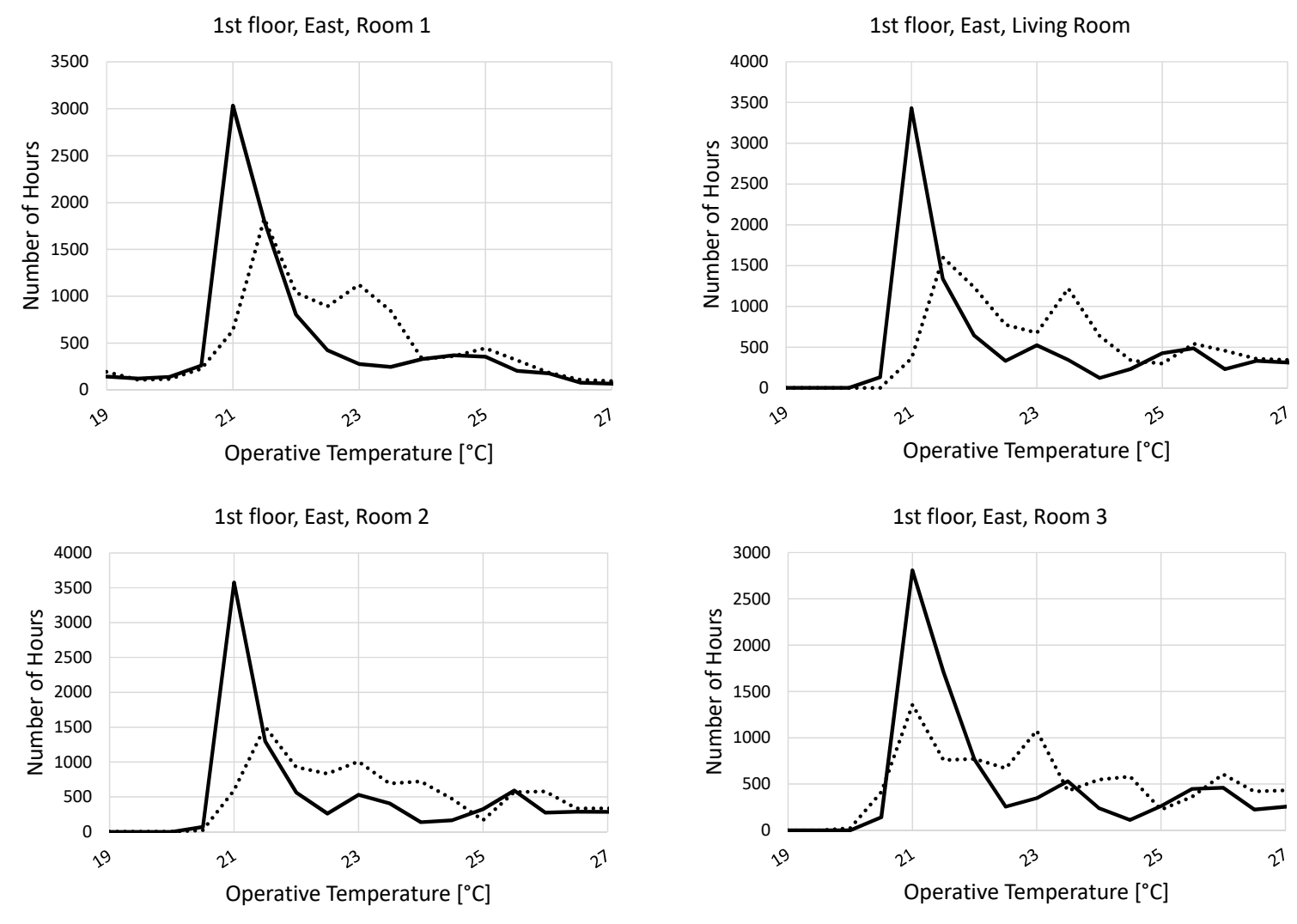

..... Ground \& 2nd Floor, Tset: $24^{\circ} \mathrm{C} \longrightarrow$ All Zones, Tset: $21^{\circ} \mathrm{C}$

…. Ground \& 2nd Floor, Tset: $24^{\circ} \mathrm{C} \longrightarrow$ All Zones, Tset: $21^{\circ} \mathrm{C}$

Fig. 18. Comparison of the temperature frequency for simulations with homogeneaous and inhomogeneaous temperature settings in apartments with reference room control. Set point temperature in the middle floor is always $21^{\circ} \mathrm{C}$.

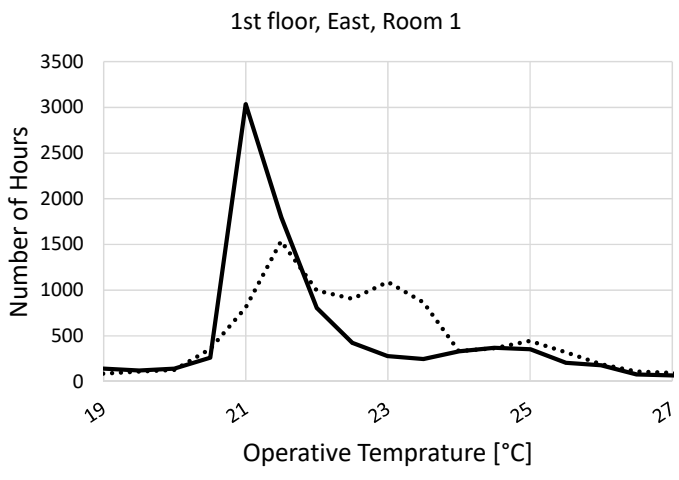

..... 1st floor, Tset: $18^{\circ} \mathrm{C}$, rest Tset: $24^{\circ} \mathrm{C}$ — All Zones, Tset: $21^{\circ} \mathrm{C}$

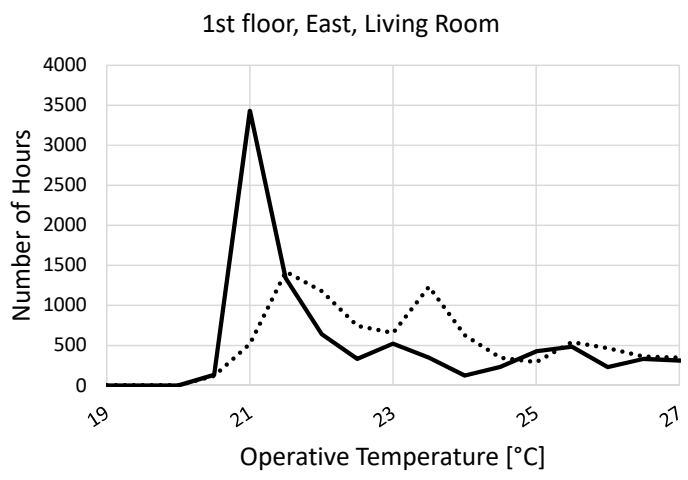

..... 1st floor, Tset: $18^{\circ} \mathrm{C}$, rest Tset: $24^{\circ} \mathrm{C}$ — All Zones, Tset: $21^{\circ} \mathrm{C}$

Fig. 19. Comparison of the temperature frequency for simulations with homogeneaous and inhomogeneaous temperature settings in apartments with reference room control. Set point temperature in the middle floor is $18^{\circ} \mathrm{C}$ ("Heating Off"). 
Table 3. Economic evaluation of the different room temperature controls for Swiss conditions. The case without room control serves as reference.

\begin{tabular}{ccccc}
\hline Parameter & Variable & $\begin{array}{c}\text { Without } \\
\text { Room Control }\end{array}$ & $\begin{array}{c}\text { Individual } \\
\text { Room Control }\end{array}$ & $\begin{array}{c}\text { Reference } \\
\text { Room Control }\end{array}$ \\
\hline $\mathrm{W}_{\mathrm{el}, \mathrm{HP}}$ & $E_{S} / E_{0}$ & $12^{`} 055 \mathrm{kWh} / \mathrm{a}$ & $8 ` 504 \mathrm{kWh} / \mathrm{a}$ & $9 ` 435 \mathrm{kWh} / \mathrm{a}$ \\
$\begin{array}{c}\text { Investment Costs } \\
\text { Maintenance Costs } \\
(1 \% \text { of Investment })\end{array}$ & $I$ & - & $19 ` 800 \mathrm{CHF}$ & $4 ` 320 \mathrm{CHF}$ \\
Payback Period & $Z$ & - & $19.8 \mathrm{CHF} / \mathrm{a}$ & $4.3 \mathrm{CHF} / \mathrm{a}$ \\
\hline Annuity Gain & $G$ & - & 25.3 years & 7.5 years \\
\hline
\end{tabular}

\subsection{Economic viability}

Tab. 3 summarises a profitability analysis for Swiss conditions using the annuity profit method (see chapter 2.5). The variant without room control serves as a reference. A capital interest rate of $3 \%$, a useful life time of 15 years and average electricity costs of 22 cent $/ \mathrm{kWh}$ were assumed. The electricity costs are an average price over 15 years, based on 20.5 cent $/ \mathrm{kWh}$ and a price increase of one percent per year [15]. The installation and material costs for the individual room control are estimated at $600 \mathrm{CHF}$ per room. For the reference room control an extra surcharge of $20 \%$ was added per apartment, because of a higher ratio of initial costs for a smaller order. The cost estimation was done by the building department of the city of Zurich. The evaluation shows that the investment pays off in the case of the reference room control $(G>0)$. However, the additional costs of an individual room control system cannot be amortized under these conditions $(G<0)$.

\section{Discussion}

Unfortunately, extensive studies on user behaviour in new buildings cannot be found in the literature. This makes it difficult to use realistic user profiles and to assume realistic user behaviour in the simulations. The assumptions made are partly based on own experience and projects regarding the so-called "Energy Performance Gap", but they are not statistically proven. Nevertheless, conclusions on final energy consumption can be made for the different control modes under the premise of the assumptions that were made, and analysed in an economic context.

The results show that the On/Off cycles of the heat pump can vary greatly depending on the room temperature control. This may have an influence on the service life of the compressor and to a lesser extent on the final energy consumption. Both were not directly taken into account in the evaluation of the economic viability. Which means that the cost-effectiveness of the reference control may be somewhat underestimated.

\section{Conclusions}

The evaluation of the simulations clearly shows that residential buildings without room temperature control have a significantly higher final energy consumption than those with room temperature control. In all cases investigated, it is not advisable to operate heating systems of buildings without room temperature control. Comfort can be maintained best with individual room control. From an economic point of view, however, the energy savings that can be achieved with an individual room control system do not pay off. The situation is different with the reference room control, which is always economical, thanks to the considerably lower investment costs, even if the energy savings are lower than with individual room control. Nevertheless, the authors would in principle recommend an individual room control. Failures like missing hydronic balancing of the floor heating distribution can be better compensated with an individual room control then with a reference room control. In the case of single-family houses the authors recommend on the basis of the results in a separate study [7] that an individual room control should always be installed.

The evaluation of the results showed also that both the heat demand and the temperatures of an apartment that is located on a floor in between two other inhabited floors are strongly influenced by the apartments above and below. If all apartments and floors have the same room temperature, then the space heating requirement for the first floor is $20 \%$ of the total of all three floors. If, however, the ground floor below and the uppermost floor above are heated with $3 \mathrm{~K}$ higher target temperatures, the proportion of heat requirement for the floor in the middle drops to $1 \%$. In addition, the temperatures in the middle floor are sometimes higher than the residents actually want, which can result in them lowering their target room temperature further or even opening the windows. This can ultimately be one of the causes of the so-called "Energy Performance Gap". In a study from Germany [16], this is referred to as "biofeedback". From personal experience, but also from discussions with colleagues at work, the topic of middle floors that are too warm has already been discussed frequently and the feedback we get largely agrees with the results of the simulations. The results show that the 
"zero heating set temperature" on the controller in the first floor is approx. $20^{\circ} \mathrm{C}$, which means that at this set point temperature the apartments in the middle are heated sufficiently (good comfort) thanks to heat transfer from the apartments above and below. This circumstance should be taken into account at least in the heating costs billing procedure. In addition, it raises the question of whether better insulation between floors would not make sense, as the building envelope is getting better and thus the heat losses to the outside are getting smaller and smaller.

The authors would like to thank the Swiss Federal Office of Energy (SFOE - EnergieSchweiz) for the financing support received under the project OpEEr.

\section{References}

1. Schweizerischer Ingenieur- und Architektenverein, SIA 384/1:2009: Heizungsanlagen in Gebäuden Grundlagen und Anforderungen, (2009).

2. European Committee for Standardization (CEN), EN 12828:2014-07: Heating systems in buildings Design for water-based heating systems, (n.d.).

3. Mustervorschriften der Kantone im Energiebereich (MuKEn 2014), (2016).

4. Directive (EU) 2018/844 of the European Parliament and the Council of 30 May 2018, (2018).

5. K.. Lomas, S. Oliveira, P. Warren, V.J. Haines, T. Chatterton, A. Beizaee, E. Prestwood, B. Gething, Do domestic heating controls save energy? A review of the evidence, Renewable and Sustainable Energy Reviews. 93 (2018) 52-75. doi:https://doi.org/10.1016/j.rser.2018.05.002.

6. I. Mojic, Einfluss von raumbasierten Regelungen auf den Raumwärmebedarf eines Einfamilienhauses mit Niedertemperatur-Verteilsystem, Lucerne University of Applied Sciences and Arts (2017).

7. I. Mojic, M. Haller, Einfluss der Einzelraumregelung auf den Raumwärmebedarf von Niedrigenergiehäusern mit hohem

Verglasungsanteil, SPF Institute for Solar Technology, Rapperswil, (2017). www.spf.ch $\backslash$ ErrEnEff

8. I. Mojic, M. Luzzatto, M. Haller, M. Lehmann, M. Benz, S. Van Velsen, ImmoGap - Einfluss der Kombination aus Nutzerverhalten und Gebäudetechnik auf den Performance Gap bei Mehrfamilienhäuser, SPF Institute for Solar Technology, Rapperswil, (2018). www.spf.ch \ImmoGap

9. I. Mojic, M. Haller, OpEEr - Optimierung der Energieeffizienz von Gebäuden durch Einzelraumtemperaturregelung, SPF Institute for Solar Technology, Rapperswil, (2018). www.spf.ch $\backslash \mathrm{OpEEr}$
10. Schweizerischer Ingenieur- und Architektenverein, SIA Merkblatt 2024: StandardNutzungsbedingungen für die Energie- und Gebäudetechnik, (2015).

11. Schweizerischer Ingenieur- und Architektenverein, SIA 384.201: Heizungsanlagen in Gebäuden Verfahren zur Berechnung der Norm-Heizlast, (2003).

12. Anwendungshilfe zu den Gebäudestandards Minergie/Minergie-P/Minergie-A, (2018).

13. European Committee for Standardization (CEN), EN 15377-1: Heating systems in buildings - Design of embedded water based surface heating and cooling systems - Part 1: Determination of the design heating and cooling capacity, (2005).

14. A. Enseling, Leitfaden zur Beurteilung der Wirtschaftlichkeit von Energiesparinvestitionen im Gebäudebestand, (2003).

15. Eidgenössische Elektrizitätskommission ElCom, Konstante Strompreise 2019 - Medienmitteilung ElCom, (2018).

16. F. Schröder, C. Ohlwärter, H. Erhorn, J. Reiss, Reale Raumtemperaturen in Mehrfamilienhäusern Korrelation mit Gebäudeenergiekennzahlen, EnEV Aktuell. Nr. 2 (2010) 17-19. 